\title{
Study on the Characteristics of MAO/Polymer/Ni Three-Layer Composite Film formed on AZ31 Magnesium Alloy
}

\author{
Hung-Bin Lee ${ }^{1}$,Hung-Hua Sheu, ${ }^{2,3}$, Jia-Sian, Jian ${ }^{1}$, Ruey-Chang Hsiao, ${ }^{4}$, \\ ${ }^{1}$ Department of Optoelectronics and Materials Technology \& Center of Excellence for Ocean \\ Engineering, National Taiwan Ocean University, Keelung 202, Taiwan, ROC. \\ ${ }^{2}$ Department of Chemical \& Materials Engineering, Chung Cheng Institute of Technology, National \\ Defense University, Dasi, Taoyuan 335, Taiwan, ROC. \\ ${ }^{3}$ System Engineering and Technology Program, National Yang Ming Chiao Tung University, Hsin- \\ Chu, 300, Taiwan, ROC. \\ ${ }^{4}$ Department of Chemical and Materials Engineering, Lunghwa University of Science and Technology, \\ Taoyuan334, Taiwan, ROC. \\ *E-mail: hrc@gm.lhu.edu.tw
}

Received: 31 August 2021 / Accepted: 18 October 2021 / Published: 10 November 2021

In this study, MAO/Polymer/Ni three-layer composite coating deposited on AZ 31 magnesium alloy was carried out by micro-arc oxidation, spinning coated and eletroless Ni processes. The characteristics of different coatings were analyzed by XRD, SEM, TEM and EDS. The MAO film subsequent sealing with polymer layer, the polymer agent will fill up the micro-arc holes of MAO film. Finally, an electroless nickel layer were deposited on polymer film to form a $\mathrm{MAO} /$ polymer/Ni composite coating. It can significantly decrease the $\mathrm{i}_{\text {corr }}$ value from $39.6 \times 10^{-6} \mathrm{~A} / \mathrm{cm}^{2}$ to $7.2 \times 10^{-6} \mathrm{~A} / \mathrm{cm}^{2}$. The $\mathrm{MAO} /$ polymer/Ni coating significantly enhanced the corrosion resistance of the AZ31alloy due to the protection performance both of polymer and nickel layer.

Keywords: AZ31 magnesium alloy, micro-arc oxidation, polymer layer, electroless nickel

\section{$\underline{\text { FULL TEXT }}$}

(C) 2021 The Authors. Published by ESG (www.electrochemsci.org). This article is an open access article distributed under the terms and conditions of the Creative Commons Attribution license (http://creativecommons.org/licenses/by/4.0/). 